\title{
The price, quality and distribution of mortgage payment protection insurance: A hedonic pricing approach
}

\author{
John K. Ashton \\ Bangor Business School \\ Bangor University \\ and \\ Robert S. Hudson \\ Hull University Business School. \\ University of Hull.
}

\begin{abstract}
Mortgage payment protection insurance (hereafter MPPI) provides varying combinations of accident, sickness and unemployment insurance and is used to protect the mortgage payments of policyholders in the event of a fall in income. Despite alleviating housing market failures, this service has been heavily criticised for providing poor value for money and being associated with unhelpful sales techniques especially when sold jointly with a mortgage in the UK. Consequently, the Competition Commission (2009) ruled that after February 2011 MPPI should not be sold jointly with mortgage lending within seven days of the credit transaction. We examine whether this prohibition was justified and if the form of distribution, either jointly with the mortgage or independently influences the premium levels. This assessment uses a hedonic pricing approach with details and premiums of MPPI policies in 2010 and 2012. Despite the success in reducing MPPI premium levels, we conclude that the Competition Commission judgement has raised concerns as to mortgagee protection.
\end{abstract}




\section{The price, quality and distribution of mortgage payment protection}

\section{insurance: A hedonic pricing approach}

\section{Introduction}

Mortgage payment protection insurance (hereafter MPPI ${ }^{1}$ ) is an 'add-on' service providing varying combinations of accident, sickness and unemployment insurance and is used to protect the mortgage payments of policyholders in the event of a reduction in income. The provision of this insurance service has long been a UK policy priority to compliment the system of state income support for mortgagors (Department for Environment, Transport and the Regions, 2000). Nonetheless, this product has been heavily criticised for providing poor value for money and for being associated with unhelpful sales techniques especially when sold jointly with a mortgage (see Office of Fair Trading, 2006 [hereafter OFT]; Competition Commission, 2007, 2008, 2009)2. In 2009 the Competition Commission ruled that after February 2011 MPPI should not be sold jointly with lending. A joint sale is defined as one within seven days of the credit agreement. We investigate if this far-reaching ruling is justified and specifically whether MPPI policies sold jointly with a base good, mortgages, are more expensive than policies sold

\footnotetext{
${ }^{1}$ Through the paper Mortgage payment protection insurance is denoted MPPI and payment protection insurance is denoted PPI. Different regulators are also referred to by their acronyms; the Office of Fair Trading as the OFT, the Financial Services Authority as the FSA and the Financial Conduct Authority as FCA.

2 The provision and regulation of private mortgage insurance has a considerable lineage and has consistently raised disparate policy concerns internationally. PPI was developed in the USA in 1917 (Baker and Siegelman, 2014) and has raised concerns since the 1950s (see Baker and Siegelman, 2014, for further discussion).
} 
independently for a given set of benefits and conditions, as predicted by regulators and extant theory (e.g. Ellison, 2004, Gabaix and Laibson, 2006).

MPPI is a highly complex service combining a number of different types of insurance and has characteristics which vary across providers. We allow for this complexity by using the hedonic regression technique formalised by Rosen (1974) as a method of deriving monetary values for the attributes of composite goods. Through examining a nearly complete population of UK MPPI policies from August 2010 and June 2012 (797 policies offered by 98 firms) we report that premium size declines together with the quality of MPPI policies, and that the take up in this market has declined. While independently and jointly distributed policies possess different characteristics, significant difference in premiums are reported, with MPPI policies sold independently having lower premiums than policies distributed jointly. The premium falls are robust to such quality changes and we conclude the Competition Commission (2009) prohibition of joint MPPI and mortgage sales is justified in terms of premium costs. Nonetheless, concerns persist as to the social welfare implications of this regulatory decision.

This investigation is important for four reasons. Firstly, there are clear economic incentives for firms distributing MPPI policies with mortgages to offer higher quality policies than firms independently distributing these policies. MPPI provides mortgage repayments in the event of a policyholder suffering a fall in income due to unemployment, critical illness or accident. In the event of a successful claim the policyholder and firm jointly providing a mortgage loan with MPPI are both beneficiaries of these pay-outs. The MPPI policyholder benefits from a pay-out in that their mortgage payments are made, they will not default on their mortgage and will not face the repossession of their home. The mortgage provider jointly distributing MPPI will also benefit through guaranteed mortgage repayments and reducing the trust required within the lending relationship (Lapavitsas, 2007). A firm jointly distributing MPPI with mortgage lending therefore benefits from a policy with inclusive coverage, greater quality 
and higher pay-outs in the case of a successful claim. Conversely, an independent supplier of MPPI is not a recipient in the case of a successful claim and has no incentives to offer a higher quality MPPI policy. Subsequently providing MPPI jointly should lead to higher quality policies than providing MPPI independently.

Secondly, while only a small proportion of households default on their mortgage debt (Figueira, Glen and Nellis, 2005) the costs of this outcome are high. For lenders mortgage default increases provisions for bad and doubtful debts. For government mortgage default can result in the re-housing the homeless and payment of housing support. For mortgagors default and repossession can significantly increase the incidence of mental illness (Pevalin, 2009) and cause emotional costs akin to marital breakdown or job loss (Taylor, Pevalin and Todd, 2007). Subsequently developing methods to reduce the number of mortgage defaults is socially and economically advantageous. MPPI has been widely promoted by successive UK governments to alleviate the problems associated with such defaults. However, the prohibition of selling MPPI jointly with credit within seven days of a sale may reduce the uptake of this form of private insurance, potentially creating wider social and economic costs.

Thirdly, while the examination of add-on goods or services and their distribution has become a significant and influential theoretical theme in industrial and competition economics, empirical assessments of these circumstances are rare (Grubb, 2015). The MPPI market is a useful test of such theory, which predicts an add-on service provided jointly with a base good of primary interest to the customer (in this case a mortgage) would be priced differently to a service distributed independently. Specifically it has been argued that distributing a good jointly will influence how customers' search for appropriate products (e.g. Ellison, 2004, Gabaix and Laibson, 2006). While the customer may actively search for the cheapest/highly quality base good, the aftermarkets for jointly sold add-on goods may display distinct competitive conditions. In such aftermarkets the conditions of sale may not be clear and the add-on goods' utility, quality 
and cost may all be obscured using complex pricing formats and small print (Piccione and Spiegler, 2012, Sato, 2014). Therefore, some customers may make a purchase decision for an add-on good without realising the costs of this action. Thus price competition can be constrained and higher prices develop. Payment Protection Insurance (hereafter PPI) stands out as an important case due to the scale of the markets involved. Through examining a market where a service is both sold as an add-on and as an independent service the application and efficacy of the underlying theory can be explored.

Lastly, at a time when questionable practices by banks in the levying of additional fees and charges for add-on services are seen globally (Tennant and Sutherland, 2014), the sale of PPI, its high profitability and the considerable costs of customer redress, make this a market worthy of further examination. The UK market for PPI peaked with around 20 million policies in operation in 2006 (OFT, 2006) and prior to the 2009 regulatory intervention, this market was highly profitable and characterised by low pay-out ratios and high commissions. Similar features existed in other national markets ${ }^{3}$. After the Competition Commission (2009) ruling a process of customer redress was initiated by the Financial Services Authority (hereafter FSA ${ }^{4}$ ). This process dealt with many of the 13 million customer complaints made about UK PPI markets and had paid out over $\AA_{2}^{20 b n}$ by July 2015 (Financial Conduct Authority, 2015, hereafter FCA). Despite the substantial costs of this regulatory process, academic work examining this judgement has to date been limited (see FCA, 2014).

This study therefore contributes to the literatures on MPPI and PPI by examining a distinct policy orientated question; whether policyholders pay more for this service when it is distributed jointly rather than independently. This question is so framed to examine the rationale of the significant regulatory intervention by the UK competition authorities into this market; an

\footnotetext{
${ }^{3}$ For example PPI pay-out ratios ranged from $40 \%$ to $80 \%$ of premiums in the USA (Federal Trade Commission, 2001) with average commissions on PPI averaging 59\% (OFT, 2006) in the over the 2000 to 2005 period in the UK.

${ }^{4}$ On 1 April 2013 the Financial Services Authority was replaced by the Financial Conduct Authority.
} 
intervention which has yet to investigated. This study, therefore, contributes to the emergent literature examining PPI markets and the impact of the significant UK regulatory intervention in 2009. Further, by examining a case where services have been distributed jointly as an add-on good and independently, theoretical predictions as to the operation of such markets may be evaluated. The regulatory decision to constrain the joint sale of an add-on good is related to concurrent developments in the economic theory of add-on goods. Lastly, this study builds on an existing literature examining MPPI, through addressing distinct consumer protection and competition concerns.

The study is organised into five sections. After this introduction we give an overview of the pertinent academic and regulatory literature. The third section outlines the data and the form of the analysis. The fourth section reports the empirical results. Lastly, we present a summary of the research, policy implications and conclusions.

\section{Literature examining mortgage payment protection insurance.}

The literature surrounding the provision of MPPI has been influenced, and to a certain degree led, by the on-going policy discussions surrounding this financial service. These debates have considered the requirements for private mortgage protection, the low take up of this service and more recently consumer protection and competitiveness concerns.

The longest standing of all MPPI policy concerns has been whether this service can be an effective private sector source of mortgagee protection. While UK governments since 1948 have supported mortgagors claiming unemployment benefits (e.g. national assistance, supplementary benefit, income support and job seekers allowance; see Ford and Quilgars, 2001) this welfare safety net was curtailed in 1987 and 1995, extended in 2009 and reduced again in 
2010. The suitability of MPPI as a 'private sector' source of mortgagee support to replace this eroding public 'safety net' has engendered much discussion. Academic examinations have focused on the perceived quality and costs of UK MPPI services reporting this service was very expensive, limited in coverage, contains regressive elements (Burchardt and Hill, 1998) and had not prevented a sizable proportion of MPPI policyholders developing mortgage arrears (Ford and England, 2000, Ford and Quilgars, 2001).

Despite such concerns MPPI has been promoted by subsequent UK governments to facilitate sustainable home ownership (e.g. Department of Environment, Transport and the Regions, 2000), enhance customer engagement with financial markets (see Moloney, 2010) and support UK government policies such as the right to buy (Ford and England, 2000). While this approach and other changes have reduced the number of households unable to access credit and subject to discriminatory practices, there has been an associated decline in the quality of UK mortgage lending overall (Stephens and Quilgars, 2008) ${ }^{5}$. MPPI has been repeatedly advanced as a convenient solution to address the challenges raised by burgeoning UK home ownership by low income households, unskilled workers and older people (Ford, 2004). Academic contributions have subsequently questioned why the take up of MPPI had been poor ${ }^{6}$, reporting a limited link between premium levels and policy demand, the experience of unemployment as a determinant of MPPI take up (Pryce and Keoghan, 2001) and the link between household savings and age of the mortgagor with the propensity to use MPPI (Ford, Quilgars, Burrows, and Rhoades, 2004).

In the USA similar concerns have been investigated. Here it has been reported that the use of MPPI raises the level of mortgage application acceptance for all groups and particularly

\footnotetext{
5 The market for MPPI also augments the cover provided by other financial services used to protect lenders from default risks and developed in response to changes in government support for mortgagors. For example, mortgage indemnity guarantees are used in the UK to cover lenders in a case of default on higher loan to value mortgages (see Stephens, 2003). This coverage is extended by MPPI to include mortgagees as well as lenders, for cases of illness, unemployment or accidents.

${ }^{6}$ The MPPI market remained one of the smaller PPI markets accounting for $f_{\mathrm{N}} 607 \mathrm{~m}$ for first mortgages and $£ 251 \mathrm{~m}$ for second mortgages and secured lending in 2007 (Competition Commission, 2009).
} 
those where racial and social characteristics might otherwise lead to discrimination or 'red-lining'. Offering MPPI therefore enables banks to satisfy legislative demands not to discriminate in mortgage lending and has resulted in many previously excluded households obtaining housing finance (Ross and Tootell, 2004). This said, mortgagees with unstable work histories and ill health problems continue to be excluded from these policies (Diaz-Serrano, 2005).

During the 2000s major regulatory assessments of MPPI and PPI markets addressed consumer protection concerns. In the UK the provision of PPI was repeatedly examined by the FSA (FSA, 2005, 2006, 2007a, 2007b) and the OFT (OFT, 2006) with matters coming to a head with the Competition Commission (2009) ruling. Specifically this ruling stated that joint sales of PPI with credit (unsecured lending, credit card debt and mortgages) are prohibited within seven days of the credit agreement, single premium insurance policies should not be employed, greater customer information provision is required and PPI should be unbundled from other financial services. This ruling and the subsequent process of customer redress was prompted by claims of mis-selling and the excessive price of PPI within a variety of credit markets. Similar regulatory concerns and debates have been witnessed in the USA involving Senate hearings in the 1970s, consideration of coercive sales (United States General Accounting Office, 1990) and the criticism of 'packing' PPI within home and consumer loans (Federal Trade Commission, 2001).

These consumer protection and competition themes within MPPI markets have received sparse attention in the academic literature with most contributions examining other PPI markets be these in the UK or the USA. For example in the UK Ranyard and McHugh (2012) examined customer decision making in PPI markets, reporting the willingness to pay for PPI is insensitive to large changes in the quality of cover. Ashton and Hudson (2014), examining unsecured lending PPI over the 1998 to 2011 period, reported that interest rates on loans were significantly lower when the loans were offered with PPI. Ferran (2012) provides a legal overview of the PPI mis-selling episode and regulatory decisions. US examinations of PPI have examined a variety of 
regulatory and policy concerns including the limited competitiveness of these markets, overpriced policies (Allen and Chan, 1998), excessive coverage provided (Cyrnak and Canner, 1986), the often very small quantities insured (Durkin and Elliehausen, 2012), tying arrangements (Polden, 1983) and the legal treatment of payment protection policies generally (Spahr and Escolas, 1986). Discussion of on-going policy issues in US PPI markets is provided by Baker and Siegelman (2014).

\section{Data and Forms of Analysis}

\subsection{The Data Employed}

The data for this study was provided by the FSA comparison website on MPPI and includes information on 275 policies provided by 60 financial services firms in August 2010 and 702 policies provided by 62 financial services firms in June 2012. The data provides policy information for monthly mortgage payments of $£, 500, £ 1,000, £ 1,500$, and $£ 2,000$ borrowed by a 20, 40 and 60 year old employed person working 40 hours per week (data for $£, 500$ borrowed by a 20 year old in 2010 and for $£ 2000$ cover on jointly distributed policies in 2012 was unavailable). As premium levels of individual policies vary with the age of the policyholder and with the loan repayment covered by the policy, each policy generates a number of different observations which vary by premium levels. Therefore, this policy information for different age and mortgage payment groups provides 3691 observations for 2010 and 6508 observations for $2012^{7}$.

\footnotetext{
7 The word 'policy' in the insurance sector can have different meanings depending on the context in which it is used. Sometimes it is used to represent a product that is offered to the market. Alternatively, this term is employed to refer to the specific contractual arrangement between an insurance company and a consumer for which a certificate or other legal document would be issued after the consumer has bought insurance. In this study we examine product level data not data at the level of individual contracts. The 275 policies represent different MPPI insurance products that would be available for consumers to purchase. The price paid for a specific product by a specific purchaser would depend on the
} 
The MPPI market examined differs from other PPI markets. Relative to other PPI markets, MPPI customers are more likely to shop around for this insurance service (OFT 2006), MPPI has received fewer complaints which have been upheld (Financial Conduct Authority, 2014) and while other PPI services insure relatively small quantities, MPPI often provides cover for significant values. The Competition Commission (2009) further reported that unlike unsecured lending and credit card PPI where no relationship between premiums and policy quality is observed a weak relationship between the premium price and policy quality exists for MPPI.

The MPPI policies were distributed either independently or jointly with a mortgage loan, with a small number of firms distributing both jointly and independently. In 201026 firms issued 34 jointly distributed policies and 38 firms issued 245 independently distributed policies. After the prohibition of joint MPPI sales within seven days of a credit agreement on the 14th February 2011, the number of jointly distributed MPPI products fell and by June 2012 only 7 firms were offering 9 policies jointly with credit (sold seven days after the initial credit agreement). In contrast 56 firms offered 694 MPPI policies independently of a credit agreement. Therefore a market structure favourable to the creation of a competitive market existed, with a greater number of independent suppliers offering a range of policies to the market and a limited number of supplier firms jointly selling a constrained range of MPPI policies.

In parallel to this change the number of policies available on the market increased considerably. In 2010 all but a handful of major mortgage providers provided MPPI policies which were jointly sold. The vast majority of customers taking out mortgages will have been targets for a jointly sold MPPI policy from the same provider. Although definitive market

circumstances of the purchaser particularly their age and the level of loan repayment covered. There are a huge number of combinations of age and loan repayment amounts so the FSA collected details for particular specimen combinations. By reporting the different premiums and policy characteristics for policies (products) offered to 20,40 and 60 year olds and for mortgage repayments of $f, 500, £, 1,000$, $£, 1,500$, and $f 2,000$ a total of 3691 different observations are generated in 2010 and 6508 observations generated in 2012. All such characteristics result in different premium values for the policies (products). 
figures are not available it is almost certain that the vast majority of MPPI contracts entered into will have involved a jointly sold policy. In 2010 the independently sold MPPI policies were largely offered by relatively small providers who did not also offer mortgages. These providers generally will have had much less market power in that they would have had much less easy access to customers at the point they were taking out a mortgage.

By 2012 most of the large mortgage providers had pulled out of the MPPI market entirely selling neither independently nor jointly. Presumably this was on the assumption that without access to customers at the point of mortgage sale, the market would no longer be attractive. Although the overall volume of MPPI contracts taken out probably dropped considerably there was potentially greater opportunities to market independently sold contracts as many more, generally relatively small firms, entered this market with new policies. The 7 firms still selling jointly only represented a small part of the mortgage market. Four are small regional building societies, two are small commercial organisations and one is a large bank although not one that has specialised in the mortgage market.

The quality of a MPPI policy depends fundamentally on the terms and conditions under which benefits are payable. The relevant terms and conditions are explained in Table 1. While this data includes all firms which provided data for the FSA site and includes an almost complete record of the population of policies issued at the time, there are omissions. Some firms have refused to have their policies listed on this website; these firms are consistent over the two data collection periods limiting any selection bias.

\section{INSERT TABLE 1}


This data is distinct from that used in past studies of MPPI (e.g. Burchardt and Hill, 1998, Ford and England, 2000, Ford and Quilgars, 2001, Ford, Quilgars, Burrows and Rhoades, 2004, 2004, Pryce and Keoghan, 2001) as it considers MPPI policy details and premiums rather than survey evidence. It is believed that this is the first study of the MPPI market to use policy data rather than survey data. This choice of data brings both benefits and drawbacks. While policy data offers comprehensive details of the attributes of the policies offered, it does not provide indications of which policies have been chosen by mortgagees or the reasons for these purchase decisions. We freely acknowledge it would be optimal to employ data on the number of policies sold as well the details of policies bought, although such data is of a proprietary nature and not publically available. We further acknowledge this data had to be collected in different months of the year following FSA decisions regarding public access to the website. While the use of data collected at different times of the year may have introduced seasonal influences into the analysis, these differences are limited by the low frequency of policy changes. A full list of the firms providing MPPI in 2010 and 2012 is provided in Appendix 1.

\subsection{The Testing Framework}

The testing framework is divided into two parts. Initially, descriptive statistics of the dataset are considered and differences between independent and joint distribution are recorded for both premiums and policy characteristics. Where appropriate differences between policies which are jointly and independently distributed are tested using $\mathrm{t}$ and $\mathrm{Z}$ tests depending on data format. In the study quality is considered as a list of attributes which come at a price. Subsequently we investigate the distribution and frequency of these attributes and how the price of a given attribute varies over time and between independent sellers and joint sellers of MPPI.

Secondly, the costs of the different policy characteristics and restrictions are quantified using a hedonic regression model. Hedonic regression techniques (Rosen, 1974) are employed as 
a method of deriving monetary values for the attributes of composite goods. Composite or differentiated goods can be described by a vector of different characteristics; these are detailed in Table 1 for the MPPI policies considered ${ }^{8}$. Table 1 also considers the way the various policy features are quantified and the sign of their expected coefficient in the regression; the expected relationship between the policy characteristic and premium size. The expected influence of these policy conditions for the pricing of MPPI premiums vary in terms of the costs or benefits of including these characteristics. A positive relationship between premiums and benefit coverage, age, maximum payments, back to day one cover, portability and acceptance of backache and stress is predicted as these will contribute to the costs of the policy. A negative relationship between premiums and the waiting periods for both unemployment and accidents and sickness are predicted, as premiums should decline as waiting periods are raised.

Rosen showed that the implicit value of characteristics can be estimated by determining how the market price of products is affected by the vector of characteristics associated with the product. Essentially, in a competitive market, the price of a product is a function of its characteristics:

$$
P(A)=P\left(a_{1}, a_{2}, \ldots, a_{n}\right)
$$

While there is no strong theoretical basis for choosing a particular functional form (see Halverson and Pollakowsji, 1981, Rosen, 1974) it is important to employ a functional form which reflects the circumstances considered by the model (see Can and Megolugbe, 1997). Following other studies examining product quality (e.g. Wilson and Wilson, 2014) and its

\footnotetext{
${ }^{8}$ We acknowledge these characteristics are incomplete and other characteristics may be influential. For example, the type of employment undertaken by a policyholder, the ability to stop and start payments on mortgages and the duration of previous employment could all affect premium costs. Sadly, information on all possible characteristics was unavailable.
} 
established position in this literature (Malpezzi, 2002) a log-linear functional form ${ }^{9}$ is employed. This model form is written as:

$$
\ln P=\beta_{0}+\beta_{1} a_{1}+\beta_{2} a_{2}+\ldots \ldots+\beta_{n} a_{n}+\varepsilon
$$

where $\ln \mathrm{P}$ is the natural logarithm of monthly premiums, $\beta_{\mathrm{i}}(\mathrm{i}=0, \ldots \mathrm{n})$ are the $\mathrm{n}$ coefficients of the hedonic regression and $\varepsilon$ is the error $\operatorname{term}^{10}$. As already mentioned, the product characteristics $a_{i}(i=0, \ldots n)$ are detailed in Table 1 .

There are empirical issues in fitting such a model. It is possible that some of the product characteristics are highly correlated, which would lead to problems with multi-collinearity, so it is appropriate to allow for this possibility which we do in the results section. In theory the model may also suffer if important product characteristics are omitted. Butler (1982) and Ozanne and Malpezzi (1985) show that the coefficients of independent variables in the hedonic equation may not be particularly robust with respect to omitted variables. Omitted variable bias, however, is likely to be modest within our investigation, as the express purpose of the FSA comparison website was to enable policies to be compared across all major product characteristics. In addition the overall predictions from hedonic models, as opposed to predictions of individual coefficients, are quite robust to problems with omitted variables (Malpezzi, 2002).

A further point of interest related to the application of a hedonic model is what is judged to be the scope of the competitive market. It is clear independently sold policies place no constraints on prospective purchasers to favour one policy over another. This situation is less

\footnotetext{
9 This model allows the monetary value of a policy to depend in part on the characteristics of the policy, has coefficients with simple and appealing interpretations, mitigates heteroskedasticity problems, is computationally simple and can incorporate considerable specification flexibility (Malpezzi, 2002).

10 As the data is considered as two separate cross sections for 2010 and 2012, concerns with time variation or spatial distribution seen in other applications of the hedonic model do not apply in this case (see Helbich, Brunauer, Vaz and Nijkamp, 2014, Tse, 2002 for further discussion).
} 
clear-cut for jointly sold policies. While some purchasers will compare the price and features of jointly sold policies with independently sold policies, this is often not the case. Therefore the independently sold policies can be assumed to be sold in a competitive market, while this is not necessarily the case for the jointly sold policies. Given this, five forms of the hedonic regression model (2) are estimated. Initially, the model is estimated for independently distributed policies which will give estimates of the coefficients which are consistent with the implicit value of the coefficients in a competitive market. The model is subsequently estimated separately for jointly distributed policies and for both types of policy combined. These estimates allow an assessment of the extent to which the coefficients are consistent with those found in the model estimated of independently distributed policies.

We then consider the relative premiums of policies, which are jointly or independently distributed. This is done using two different approaches which are consistent with different assumptions about market scope. The first approach assumes that all policies, however sold, form part of a single competitive market and the value of any particular product attribute can be found in that market (scenario i). This is undertaken by estimating equation (2) for all policies using a dummy variable in the regression to denote independently distributed policies. This procedure allows comparison with estimates derived using all policies to determine whether independent policies are indeed cheaper than jointly distributed policies, taking account of their policy characteristics. The second approach assumes that jointly sold policies do not form part of a competitive market and so the value of product attributes should be obtained from independently sold policies (scenario ii). This is done by estimating equation (2) for all policies whilst constraining the coefficients in the regression to be equal to the corresponding coefficients when only independent policies are included whilst also using a dummy variable to denote independent policies. This procedure allows direct measurement of the premium savings available if policies with the same features as those currently sold jointly were instead purchased in a competitive market. In both scenarios to determine the expected monetary saving of buying 
a policy independently instead of jointly we algebraically manipulate equation (2). This manipulation shows that the independent cost is a factor of $\mathrm{e}^{-\mathrm{D}}$ of the joint cost, where $\mathrm{D}$ is the coefficient of the independent distribution dummy variable in Panel D and E of Tables 4 and 5.

\section{Results}

\subsection{Descriptive Assessment}

A descriptive assessment of the MPPI premium levels is provided in Table 2. This table is divided into Panel A and B for 2010 and 2012 respectively. In Panel A premium costs rise with the level of cover. In addition, the age of MPPI policyholders influences the premium costs for policies sold independently, with younger applicants paying less for MPPI policies. This probably reflects both a smaller chance of younger applicants suffering illness and the chance of older applicants selecting against the insurers. This selection would occur when older applicants with an existing mortgage seek to buy this insurance because of private knowledge that their circumstances have changed such that they are more likely to make a claim. This age effect is not observed for the jointly sold policies, possibly reflecting a lower incidence of older people taking out mortgages which makes setting appropriate rates less material, but also because the individuals taking out these polices will be less likely to select against the insurers. At ages 20 and 40 the cost of policies sold independently tends to be lower (often at statistically significantly levels) than jointly sold MPPI policies.

INSERT TABLE 2 
For Panel B considering 2012 we observe that premiums generally increase with age for independently but not jointly sold policies. At ages 20 and 40 independently distributed policies are again cheaper than jointly distributed MPPI policies. Comparing the premium costs in 2010 and 2012 we observe that all jointly distributed policy premiums fall between 3 and 20 per cent between August 2010 and June 2012. Premium changes, although not always reductions, are also observed for most age and coverage categories for independently distributed policies with changes varying from 16 per cent premium increases to 19 per cent falls in premium levels ${ }^{11}$. In Panel $\mathrm{C}$ of Table 2, $\mathrm{t}$ tests are used to quantify the statistical significance of these differences between 2010 and 2012 premium levels. In 7 of 11 age and coverage categories there are significant differences in premium levels. Significant falls in premiums are also recorded for jointly and independently distributed policies in some age and coverage groups. Notwithstanding quality differences between policies, MPPI premiums have tended to decline to a significant extent since the 2011 prohibition of joint sales within seven days of the credit agreement.

The quality of MPPI policies is reported in Table 3. Again this table is divided into two panels for 2010 and 2012. Neither set of jointly or independently distributed MPPI policies provides a dominant set of benefits in either year. On average the policies sold jointly provide a lower maximum number of monthly mortgage payments. Little difference is observed between jointly and independently distributed MPPI policies for other attributes; for example the provision of cover to day one of the initial claim and whether pre-existing conditions are excluded or otherwise. It can be seen, however, that the incidence of beneficial policy attributes does reflect the priorities of the institution that sold it. As discussed above firms selling policies independently are much more exposed to selection and so it is not surprising that independently sold policies have substantially longer waiting periods. Independently sold policies are also far

\footnotetext{
${ }^{11}$ These premium changes are not adjusted for inflation; when considering the effect of inflation this fall in premiums is more pronounced. One widely used measure of inflation, the Consumer Price Index rose 6.44\% between August 2010 and June 2012 - figures are from the UK Office for National Statistics.
} 
more likely to be portable than jointly sold policies. This may reflect firms distributing MPPI policies jointly desiring to retain mortgagors. Independently sold policies also tend to offer additional benefits and are much less likely to cover claims due to backache and stress in 2010 .

\section{INSERT TABLE 3}

Comparing Panels A and B, a range of differences between 2010 and 2012 are observed. A number of the policy characteristics have changed in nature, or frequency of occurrence, in such a way as to indicate policy quality may have declined. For example the maximum number of payments has fallen, back to day one cover is included in a lower proportion of policies and waiting times before claims has risen on average. Other policy characteristics have remained unchanged such as the potential to access additional benefits. Lastly, the portability of policies has risen after the prohibition of joint sales. We can also observe in 2012 the 'quality' differences between independent and jointly sold policies have declined, with fewer significant differences observed between jointly and independently distributed policies in 2012, than in 2010. Further, the effect of the prohibition on joint sales within seven days, has been to reduce the incidence of many beneficial policy attributes of jointly sold policies.

\subsection{Results of the Hedonic Pricing Model}

Before applying the hedonic pricing model we consider whether there will be problems with multi-collinearity by examining the correlations between the various product features. These are shown in the two panels of Table 4 which relate to 2010 and 2012 respectively. There are elements of correlation between the features which are statistically significant although these are generally not very large in magnitude. The only features that show very high levels of correlation 
are coverage of stress and coverage of backache. Consequently coverage of stress is suppressed in the subsequent hedonic regressions to avoid issues with multi-collinearity. All the other features are retained in the hedonic regressions as the overall fit of the model is more important for our investigation that the precise magnitude of the coefficients of particular features.

\section{INSERT TABLE 4}

The hedonic regression model results are reported in Tables 5 and 6 for 2010 and 2012 respectively. In each table we report model results for all annual observations, jointly and independently distributed policies and further models to examine the influence of joint or independent distribution of MPPI policies. In both Tables 5 and 6 Panel A shows the results of the hedonic regressions for the independent policies. The market for these policies can be classified as competitive so the theoretical analysis of Rosen (1974) will be applicable. The regression is highly satisfactory with most coefficients being significant and having the expected signs, in accordance with the last column of Table 1 , in both years. The overall equation is significant at a very high level and has an $\mathrm{R}^{2}$ statistic in the region of 70 per cent for 2010 and 2012.

Panel B in both tables shows the results of the hedonic regression for the jointly sold policies. The market for these policies may not be fully competitive so the theoretical analysis of Rosen (1974) may not be totally applicable. Nonetheless the regression for 2010 is satisfactory in many respects in that most of the coefficients are significant and have the expected signs. Due to the limited number of observations employed, the results for 2012 (Table 6) are limited with a number of omitted variables. The overall equation is significant with $\mathrm{R}^{2}$ statistics of over 80 per cent for 2010 and 90 per cent for 2012 . 
Panel $\mathrm{C}$ for Tables 5 and 6 shows the results of the hedonic regression for all the policies. Again the market for the jointly sold policies may not be fully competitive so the theoretical analysis of Rosen (1974) may not be fully applicable. Nonetheless the regression still has coefficients with the expected signs and generally a very high level of significance. The overall equation is significant at a very high level and has an $\mathrm{R}^{2}$ statistics in the region of $70 \%$ for both years.

Panel D for both Tables shows the results of the hedonic regression for all policies with a dummy for policies that are sold independently. This allows comparison with Panel C to see if independent policies are indeed cheaper than jointly distributed policies, when taking account of their policy characteristics in a competitive market (scenario i). In 2010 the dummy for independent policies is negative and significant showing that these policies are 12.81 per cent cheaper for a given set of policy characteristics than jointly distributed policies. For 2012 a positive but statistically insignificant estimate is recorded which indicates independently distributed MPPI policies are no longer cheaper than jointly distributed policies.

Panel E for both Tables 5 and 6 shows the results of the hedonic regression for all the policies with a dummy for policies that are sold independently and with the regression coefficients for policy features constrained to be equal to those found in the hedonic regression for independently sold policies. This allows a direct measure of the premium savings available if policies with the same features as those currently sold jointly were instead purchased in a competitive market (scenario ii). The dummy for independent policies is negative and significant in 2010 showing that policies with a given set of features would be 13.483 per cent cheaper in a competitive market only containing independently distributed products. In 2012 this result is statistically insignificant indicating independently distributed policies are no longer significantly cheaper than jointly distributed policies. 


\section{INSERT TABLES 5 \& 6}

As previously discussed, the hedonic regression model assumes that all the policies operate in a competitive market, so whether the unconstrained or constrained regression provides the more appropriate results depends on the scope of the competitive market, in particular, whether the jointly sold policies can be considered to be being sold in a competitive market. It seems unlikely that the jointly sold policies can be considered to be competing entirely on equal terms with independently sold policies, so the results of the constraint regression shown in Panel E are likely to be the more appropriate. However, the results obtained for scenario i) and ii) (reported in Panels D and E) are actually very similar so our result is empirically and qualitatively robust to the theoretical market scope consideration. For 2010 we can deduce that the independently sold policies are between 12.81 and 13.48 per cent cheaper than those MPPI policies sold jointly. Comparable estimates for 2012 indicate independently sold policies are between 3.34 per cent cheaper and 4.92 per cent more expensive than those MPPI policies sold jointly, although these estimates are not significantly different from zero. We can conclude that in 2012 there is no significant difference between the prices of independently and jointly sold policies.

\section{Conclusions}

This study uses a hedonic pricing model to investigate the interactions between the premiums, policy quality and distribution of mortgage protection insurance (MPPI). This study addresses whether MPPI is relatively expensive when these policies are distributed jointly with mortgages relative to being distributed independently of mortgage sales. In this concluding section we 
consider a brief summary of the study findings, the pertinence of policy responses and recommendations for further work.

We report that MPPI policies sold independently had lower premiums in the age range where people are likely to be taking out mortgages. Policy characteristics and conditions vary between policies sold jointly and those sold independently. One group of policies is not dominant in this respect but the conditions reflect the circumstances of the institutions providing them. Hedonic analysis of the independently sold policies indicates that their premiums reflect the quality of the policy in terms of its coverage and conditions. The policies sold jointly are clearly more expensive for a given set of benefits and conditions than policies sold independently in 2010, suggesting uncompetitive premium levels. Further, after the prohibition of the joint sale of MPPI with mortgages within seven days of the credit agreement, the incidence of beneficial policy attributes declines and the inflated cost of jointly distributed policies dissipates.

In light of this assessment the Competition Commission (2009) prohibition of joint sales of MPPI policies within seven days of a mortgage transaction may be justified in terms of reducing premium costs, yet may not be an optimal solution for the UK housing market. While our analysis supports the conclusions of the Competition Commission (2009) regarding the excessive premiums of jointly sold MPPI policies we consider MPPI to be a special case due to its social and economic importance. The policy challenge is whether policies supporting financial responsibility are subsidiary to the consumer protection and competition concerns raised by the Competition Commission. The prohibition of joint MPPI sales has reduced the quality of many policies and will at least disrupt a market aimed at providing a private insurance 'safety net' for mortgagors; a form of insurance advocated and promoted by successive governments. In this case consumer protection concerns appear to have been more influential than policy initiatives to enhance personal financial responsibility. While we have found that jointly distributed add-on 
services are more expensive, as predicted by extant theory (e.g. Ellison, 2004, Gabaix and Laibson, 2006, removing joint sales can also result in less predictable outcomes. Indeed we are aware that the change will have social welfare implications.

Clearly further research is required to assess the longer-term influence of this prohibition. Questions requiring further assessment include whether the take-up of MPPI has declined further and if this market is viable going forward given that almost all large mortgage providers have pulled entirely out of the MPPI market. If this market has become an irrelevance since the Competition Commission prohibition, what methods and financial services are developing to replace MPPI to ensure housing finance is available to all (see Gibbs, Maclennan and Stephens, 2013, FSA, 2013). Determining the efficacy of any new methods of mortgagee support and their impact on both lenders and mortgagees is essential. Notwithstanding the high costs and often sub-optimal methods by which MPPI was distributed, this service did constrain many of the challenges facing participants in the UK mortgage market including high house prices, variable forms of mortgage contract and growing mortgagee uncertainty. It is hoped the prohibition of MPPI will not disadvantage mortgagees in navigating these on-going challenges due to a prohibition arising from the poor behaviour of lenders. 


\section{References}

Allen, D.S. and Chan T. S. (1997). The Efficiency of Residential Mortgage Guarantee Insurance Markets, The Federal Reserve Bank of St. Louis Working Paper Series, 1997-013A, The Federal Reserve Bank of St. Louis.

Ashton, J. K. and Hudson, R. (2014). Do lenders cross subsidise loans by selling payment protection insurance?, International Journal of the Economics of Business. 21(1), 121-138.

Baker, T. and Siegelman, P. (2014). 'You want Insurance with That?', Using Behavioral Economics to Protect Consumers from Add-On Insurance Products. Connecticut Insurance Law Journal, 29(1): 1- 60.

Burchardt, T. and Hill, J. (1998). From Public to Private: The case of Mortgage Payment Insurance in Great Britain, Housing Studies, 13(3), 311-323.

Butler, R. V. (1982). The Specification of Hedonic Indexes for Urban Housing. Land Economics, 58(1), 96-108.

Can, A. and Megolugbe, I. (1997). Spatial Dependence and House Price Index Construction, Journal of Real Estate Finance and Economics, 14(1-2), 203-222.

Competition Commission. (2009). Market investigation into payment protection insurance, London.

Cyrnak, A. W. and Canner, G. B. (1986). Federal Reserve Bank of San Francisco, Economic Review, 3 (Summer): p.1-20.

Department for Environment, Transport and the Regions. (2000). Quality and Choice: A Decent Home for All. The Green Paper, HMSO, London.

Diaz-Serrano, L. (2005). Income volatility and residential mortgage delinquency across the EU, Journal of Housing Economics, 14(3), 153-177.

Durkin, T. A. and Elliehausen, G. (2012). Consumers and Debt Protection Protects: Results of a New Consumer Survey, Federal Reserve Bulletin, 98(9): 1-10.

Ellison, G. (2004). A Model of Add on Pricing, Quarterly Journal of Economics, 120(2): 585637.

Federal Trade Commission. (2001). Prepared Statement of the Federal Trade Commission before the California State Assembly Committee on Banking and Finance on Predatory Lending Practices in the Home-Equity Lending Market. Federal Trade Commission, Washington.

Ferran, E. (2012). Regulatory lessons from the payment protection insurance mis-selling scandal in the UK. European Business Organization Law Review, 13(2): 247-70.

Figueira, C., Glen, J. and Nellis, J. (2005). A Dynamic Analysis of Mortgage Arrears in the UK Housing market, Urban Studies, 42(10), 1755-1769. 
Financial Conduct Authority. (2014). Redress for payment protection insurance (PPI) mis-sales. Update on progress and looking ahead. Thematic Review, TR14/14, August, London.

Financial Conduct Authority (2015). Monthly PPI refunds and Compensation, http://www.fca.org.uk/consumers/financial-services-products/insurance/paymentprotection-insurance/ppi-compensation-refunds. Accessed 4th September 2015.

Financial Services Authority. (2005). The sale of payment protection insurance - results of thematic work, November, London

Financial Services Authority. (2006). Financial Capability in the UK: Establishing a Baseline. The Financial Services Authority London.

Financial Services Authority. (2007a). The sale of payment protection insurance. Thematic update, September, London

Financial Services Authority. (2007b). The sale of payment protection insurance - phase III mystery shopping results Consumer Research 61, September, London.

Financial Services Authority. (2007c). Insurance selling and administration. Feedback on CP07 and final rules, Policy Statement 07/24, December, London.

Financial Services Authority. (2008). Consumer Responsibility, Discussion Paper, 08/5, London.

Financial Services Authority. (2010). The assessment and redress of Payment Protection Insurance complaints, Consultation Paper 10/6, London.

Financial Services Authority. (2013). Finalised Guidance. Payment Protection Insurance. FSA/OFT Joint Guidance, FSA13/02/OFT1474, London.

Ford, J. and England J. (2000). Data and Literature on Mortgage Interest: State Provision and Private Insurance, Department for Social Security, In-House Report 65, ref. 962-8557.

Ford, J. and Quilgars, D. (2000). Financial Intermediaries and Mortgage Payment Protection Insurance, Joseph Rowntree Foundation, York.

Ford, J. and Quilgars, D. (2001). Failing Home Owners? The Effectiveness of Public and Private Safety-nets, Housing Studies, 16(2), 147-162.

Ford, J., Quilgars, D., Burrows, R. and Rhoades, D. (2004). Home Owners Risk and Safety-Nets. Mortgage Payment Protection Insurance (MPPI) and beyond, Office of the Deputy Prime Minister, London.

Gabaix, X. and Laibson D. (2006). Shrouded Attributes, Consumer Myopia, and Information Suppression in Competitive Markets, The Quarterly Journal of Economics, 121(2): 505-540.

Gibb, K. Maclennan, D. and Stephens M. (2013). Innovative Financing of Affordable Housing, Joseph Rowntree Foundation, March.

Grubb, M. D. (2015). Failing to Choose the Best Price: Theory Evidence and Policy. Review of Industrial Organisation, 47(3), 303-340. 
Halverson, R. and Pollakowski, H. O. (1981). Choice of Functional Form for Hedonic Price Equations, Journal of Urban Economics, 10(1), 37-55.

Helbich, M., Brunauer, W., Vaz, E. and Nijkamp, P. (2014). Spatial Heterogeneity in Hedonic House Price Models: The Case of Austria, Urban Studies, 51(2), 390-411.

Huck, S. and Zhou, J. (2011). Consumer behavioural biases in competition: A survey. Office of Fair Trading, OFT 1324, London.

Lapavitsas, C. (2007). Information and trust as social aspects of credit, Economy and Society, 36(3), 416-436.

Malpezzi, S. (2002). Hedonic Pricing Models: A Selective and Applied Review, in Housing Economics: Essays in Honor of Duncan MacLennan, ed. Gibb K. and O’Sullivan A.

Moloney, N. (2010). Regulating the Retail Markets: Law, Policy, and the Financial Crisis. Current Legal Problems, 63(1), 375-447.

Ozanne, L. and Malpezzi S. (1985) The Efficacy of Hedonic Estimation with the Annual Housing Survey: Evidence from the Demand Experiment. Journal of Economic and Social Measurement, 13(2), 153-72.

Pevalin, D. J. (2009). Housing repossessions, evictions and common mental illness in the UK: results from a household panel study, Journal of Epidemiology and Community Health, 63(11), 949-951.

Piccione, M. and Spiegler, R. (2012). Price Competition under Limited Comparability. Quarterly Journal of Economics, 127(1), 97-135.

Polden, D. J. (1983). The Antitrust Implications of Credit Insurance Tying Arrangements, Drake Law Review, 32, 861-912.

Pyrce G. and Keoghan, M. (2002). Theory and Estimation of the Mortgage Payment Protection Insurance Decision, Scottish Journal of Political Economy, 49(2), 216-234.

Ranyard, R. and McHugh, S. (2012). Bounded rationality in credit consumers' payment protection insurance decisions: the effect of relative cost and level of cover, Journal of Risk Research, 15(8), 937-950

Rosen, S. (1974). Hedonic Prices and Implicit Markets: Product Differentiation in Pure Competition, The Journal of Political Economy, 82(1): 34-55.

Ross, S. L. and Tootell, G. M. B. (2004). Redlining, and the Community Reinvestment Act, and private mortgage insurance, Journal of Urban Economics, 55(2): 278-297.

Sato, Y. (2014). Opacity in Financial Markets. The Review of Financial Studies, 27(12): 35023546.

Spiegler, R. (2011). Bounded Rationality and Industrial Organization, Oxford University Press, New York. 
Stephens, M. and Quilgars, D. (2008). Sub-prime Mortgage lending in the UK, European Journal of Housing Policy, 8(2): 197-215.

Spahr, R. W. and Escolas, E. L. (1986). Mortgage Guaranty Insurance: A Unique Style of Insurance, Journal of Risk and Insurance, 53(2): 308-319.

Taylor, M. P., Pevalin, D. J. and Todd, J. (2007). The psychological costs of unsustainable housing commitments, Psychological Medicine, 37(7): 1027-1036.

Tennant, D. and Sutherland, R. (2014). What types of banks profit most from fees charged? A cross-county examination of bank-specific and country level determinants, Journal of Banking and Finance, 49(December): 178-190.

Tse, R. Y. C. (2002). Estimating Neighbourhood effects in House Prices: Towards a New Hedonic Model Approach, Urban Studies, 39(7): 1165-1180.

United States General Accounting Office (1990). Bank Powers. Issues relating to Banks Selling Insurance. Report to the Chairman, Committee on Small Business, House of Representatives, Reference GAO/GGD-90-113. Washington DC.

Wilson, A. P. and Wilson N. L. W. (2014). The economics of quality in the speciality coffee industry: insights from the Cup of Excellence auction programmes, Agricultural Economics, 45 (supplement): 91-105. 